\title{
Characterisation of the GRAF gene promoter and its methylation in patients with acute myeloid leukaemia and myelodysplastic syndrome
}

\author{
SE Bojesen ${ }^{1,8}$, O Ammerpohl ${ }^{2,8}$, A Weinhäusl ${ }^{3}$, OA Haas ${ }^{4}$, H Mettal $^{5}$, RM Bohle $^{6}$, A Borkhardt ${ }^{7}$ and U Fuchs ${ }^{*, 7}$ \\ 'Department of Clinical Biochemistry, Copenhagen University Hospital, Herlev, Denmark; ${ }^{2}$ University Hospital of Schleswig-Holstein, Clinic for General \\ Surgery and Thoracic Surgery, Kiel, Germany; ${ }^{3}$ ARCS, Austrian Research Center, Seibersdorf, Austria; ${ }^{4}$ CCRI, Vienna, Austria; ${ }^{5}$ University Hospital of \\ Tübingen, Clinic for Anaesthesiology and transfusion medicine, Tübingen, Germany; ' University Hospital of Giessen, Institute of Pathology, Giessen, \\ Germany; ${ }^{7}$ Dr von Haunersches Kinderspital, Department of Haematology/Oncology, Munich, Germany
}

\begin{abstract}
We report the isolation of the $5^{\prime}$ flanking region of GRAF (GTPase regulator associated with the focal adhesion kinase), previously described as a putative tumour suppressor gene of acute myelogenous leukaemia and myelodysplastic syndrome, and demonstrate its promoter activity in reporter gene assays. Two putative protein-binding sites are identified of which one was sensitive to CpG methylation. The suppressed GRAF expression could be restored in leukaemia cell lines by treatment with a demethylating agent and an inhibitor of histone deacetylases. In contrast to normal tissues, which tested negative for GRAF promoter methylation, II of 29 (38\%) bone marrow samples from patients with acute myeloid leukaemia or myelodysplastic syndrome were positive. British Journal of Cancer (2006) 94, 323-332. doi: I 0. I038/sj.bjc.6602939 www.bjcancer.com

Published online 10 January 2006

(C) 2006 Cancer Research UK
\end{abstract}

Keywords: GRAF; AML; promoter methylation; MDS

The GRAF (GTPase regulator associated with the focal adhesion kinase) gene at chromosome $5 \mathrm{q} 31$ has been identified as a translocation partner of $M L L$ (also known as $A L L-1, H R X$ or $H T R X$ ) in a case of juvenile myelomonocytic leukaemia (Borkhardt et al, 2000). GRAF has some unusual features with regard to its tumour suppressor properties. It is localised in the cytoplasm and negatively regulates the small GTP-binding protein RhoA (Hildebrand et al, 1996), which in turn is well known for its growth-promoting effect in RAS-mediated malignant transformation (Qiu et al, 1995).

GRAF function is affected by mutations and deletions of the gene in patients with acute myeloid leukaemia (AML) or myelodysplastic syndrome (MDS) (Borkhardt et al, 2000) and we hypothesised that GRAF function could also be affected by downregulation induced by methylation of its promoting regions as shown for established tumour suppressor genes (e.g. $h M L H 1$, HIC1, E-cad, VHL, CDKN2, RB, BRCA1) (Herman et al, 1994, 1998; Gonzalez-Zulueta et al, 1995; Yoshiura et al, 1995; Dobrovic and Simpfendorfer, 1997; Graff et al, 1997; Jarrard et al, 1997; Ohtani-Fujita et al, 1997; Melki et al, 1999). Thus, we isolated the $5^{\prime}$ regulatory region of GRAF by genome walking, characterised it by reporter gene assays and looked therein for methylationsensitive protein-binding sites. We tested partially and fully

\footnotetext{
* Correspondence: $\operatorname{Dr} \cup$ Fuchs, Dr von Haunersches Kinderspital, Department of Haematology/Oncology, Lindwurmstrasse 2a, 80337 Munich, Germany; E-mail: uta.fuchs@med.uni-muenchen.de

${ }^{8}$ These authors contributed equally to this study

Received 18 August 2005; revised 28 November 2005; accepted 2

December 2005; published online 10 January 2006
}

methylated alleles of the GRAF promoter by luciferase reporter gene assays. The influence of epigenetic modifications on the GRAF expression was further studied by quantitative PCR in leukaemia and lymphoma cell lines of different origin after treatment with the demethylating agent 5 -aza- $2^{\prime}$-deoxycytidine (5-azadC) or the histone deacetylase inhibitor trichostatin A (TSA).

Finally, we screened a series of bone marrow samples from patients with AML or MDS by methylation-sensitive PCR (MSPCR).

\section{MATERIALS AND METHODS}

\section{$5^{\prime}$ rapid amplification of cloned ends}

PCR products generated by a nested $5^{\prime}$ rapid amplification of cloned ends (RACE) with gene-specific primers (Table 1) against adaptor primers on an adaptor-ligated cDNA library from the cell line K562 (Clontech, Palo Alto, CA, USA) according to the manufacturer's specifications were cloned into pBluescriptIISK + (Stratagene, Heidelberg, Germany). The five longest of 25 clones from three independent PCR experiments were sequenced (ABI/ Perkin-Elmer, Langen, Germany).

\section{Genome walking and construction of reporter plasmids}

The genome walking was performed as a nested hot-start longrange PCR (conditions available upon request) with the five human templates from the Genome Walker kit \#K1803-1 (Clontech, Palo Alto, CA, USA). PCR products were cloned and sequenced. The sequence of the $5^{\prime}$ region thus obtained was used 
Table I Primer list

\begin{tabular}{|c|c|c|}
\hline Assay & Orientation & Nucleotide sequence $\left(5^{\prime} \rightarrow 3^{\prime}\right)$ \\
\hline \multicolumn{3}{|c|}{ Rapid amplification of cloned ends } \\
\hline I & Adaptor primer I, forward & CCATCCTAATACGACTCACTATAGGGC \\
\hline I & Gene-specific primer I, reverse & AATTTGTTGGTCTTGTCCAGCTCTGCTTCGTGCG \\
\hline 2 & Adaptor primer 2, forward & ACTCACTATAGGGCTCGAGCGGC \\
\hline 2 & Gene-specific primer 2, reverse & GCACCGCGGCTTGAGCGTCTCTCGGAAGTGCGGACTATCGAG \\
\hline \multicolumn{3}{|c|}{ Methylation-sensitive PCR } \\
\hline I & Forward & GATTAAGATCGCGGAAGGGTCG \\
\hline I & Reverse & AACTCTCGACAACCTCGAACGC \\
\hline 2 & Forward & CGTTITCGGGCGGTTTGAGGGTC \\
\hline 2 & Reverse & ССТСТСACAACAACCTCGACCG \\
\hline \multicolumn{3}{|c|}{ Real-time $P C R$} \\
\hline I & GRAF-F & CAGAACATTGTCATTGAGATCCTAATAGA \\
\hline I & GRAF-R & GGGCATTGGTGAGAGGCATA \\
\hline I & GRAF probe & AACCACGAAAAGATATTTAACACCGTGCCCGA \\
\hline I & $A B L-F$ & CAACACTGCTTCTGATGGCAA \\
\hline । & $A B L-R$ & CGGCCACCGTTGAATGAT \\
\hline I & $\mathrm{ABL}$ probe & CAACACCCTGGCCGAGTTGGTTCAT \\
\hline
\end{tabular}

to generate PCR fragments, which were cloned into the pGL3-Basic vector using the restriction sites HindIII and BglII. Plasmids were sequenced before proceeding to the dual luciferase assay.

\section{Cell cultivation and transfection}

The human chronic myeloid leukaemia cell line K562 was cultured in RPMI 1640 medium (Gibco BRL, Karlsruhe, Germany) supplemented with $10 \%$ fetal calf serum, $260 \mathrm{mgl}^{-1}$ L-glutamine, $50000 \mathrm{Ul}^{-1}$ penicillin and $50 \mathrm{mgl}^{-1}$ streptomycin. The cells were split $1: 10$ once a week and split $1: 104$ days before each transfection experiment.

RAW264 is a murine macrophage cell line and was cultured in DMEM (Gibco BRL, Karlsruhe, Germany) supplemented with $10 \%$ fetal calf serum, $260 \mathrm{mg} \mathrm{l}^{-1}$ L-glutamine, $50000 \mathrm{Ul}^{-1}$ penicillin and $50 \mathrm{mgl}^{-1}$ streptomycin.

Daudi was established from a Burkitt's lymphoma. Jurkat is a human T-cell leukaemia cell line. Kasumi-1 was derived from an AML (M2) harbouring a $t(8 ; 21)$. Mutz-1 was established from a patient with MDS and Fanconi anaemia. These cell lines were cultivated under the same conditions as K562.

Trichostatin A was dissolved in ethanol and added to the cell medium (RPMI or DMEM) to an end concentration of $100-300 \mathrm{ng} \mathrm{ml}^{-1}$.

\section{Reporter gene assays}

K562 cells were transiently transfected with DMRIE-C (Gibco BRL, Karlsruhe, Germany). Reporter gene assays were performed using the dual luciferase reporter assay system (Promega, Mannheim, Germany) as described by the manufacturer. In short, the cells were co-transfected with two different plasmids, each coding for a luciferase: the Renilla luciferase coded for by the pRL-TK plasmid and the firefly luciferase coded for by the pGL3 plasmid. The two enzymes each have high specificity to their own substrates with minimal low cross-activities. For each transfection experiment, the activity of each enzyme was measured sequentially in a luminometer (AutoLumat LB953, Berthold, Bad Wildbad, Germany). The pRL-TK plasmid served as an internal control for each transfection, correcting for varying transfection efficiency. The relative activity of the pGL3 plasmid containing various fragments of the GRAF promoter was normalised against the activity of the SV40 promoter $(=100 \%$; Figure $1 \mathrm{~B})$ or the activity of the empty pGL3 plasmid ( $=1$; Figure $3 \mathrm{D}$ and $\mathrm{E}$ ).

\section{In vitro modifications of the GRAF promoter}

A $40 \mu \mathrm{g}$ portion of the pGL3-Basic plasmid containing the -986 to -1 fragment of the GRAF promoter was digested with BglII and HindIII and separated by electrophoresis. The promoter fragment was excised from the agarose gel, purified and resolved. The fragment was methylated by M.SssI methylase (New England Biolabs, Schwalbach, Germany) with $10 \mathrm{U}$ enzyme $\mu \mathrm{g}^{-1}$ DNA in the presence of $320 \mu \mathrm{m} S$-adenosylmethionine (New England Biolabs, Schwalbach, Germany) for $60 \mathrm{~min}$ at $37^{\circ} \mathrm{C}$. The methylation was controlled by digestion with the methylation-sensitive restriction enzyme BstUI. The methylated DNA fragment and an unmethylated control fragment were each ligated into the pGL3-Basic vector prepared by BglII/HindIII digestion. After ligation had been confirmed by agarose gel analysis, the ligation mixture was purified using the Plasmid Mini Kit (Qiagen, Hilden, Germany). A $1 \mu \mathrm{g}$ portion was subsequently used for the dual luciferase assay (Figure 1B) as described above.

For the DNase I protection assays, the methyltransferases M.SssI and M.FnuDII (New England Biolabs, Schwalbach, Germany) were used to methylate the promoter fragments according to the manufacturer's protocol.

The plasmid constructs with deleted putative DNA-proteinbinding sites (Figure 3D) were generated by site-directed PCR mutagenesis according to Weiner et al (1994).

\section{Preparation of nuclear extracts and DNase I protection assays}

Nuclear protein extracts from RAW264 and K562 cells were prepared as described previously (Dignam et al, 1983; Shapiro et al, 1988). Briefly, after nearly reaching confluence, cells from 100 cell culture dishes $(15 \mathrm{~cm})$ were harvested and resuspended in hypotonic buffer (for buffer compositions, see Supplementary Table C). Nuclei were released and sucrose restore buffer was added. After pelleting and lysing the nuclei by adding nuclear resuspension buffer, debris was removed by centrifugation and nuclear proteins were precipitated. Finally, the nuclear extract was dialysed against buffer $\mathrm{D}$, aliquoted and stored at $-80^{\circ} \mathrm{C}$ until use.

The unmethylated or methylated (by M.FnuDII or M.SssI) promoter fragment $(-576$ to -75$)$ was released from $10 \mu$ g plasmid DNA by a BglII and HindIII digest and radioactively end-labelled with $15 \mathrm{U}$ Klenow fragment in the presence of $50 \mu \mathrm{Ci}\left[\alpha_{-}{ }^{32} \mathrm{P}\right] \mathrm{dGTP}$ and non-radioactive dATP, dCTP and dTTP. The promoter fragment was isolated by agarose gel electrophoresis and 
A
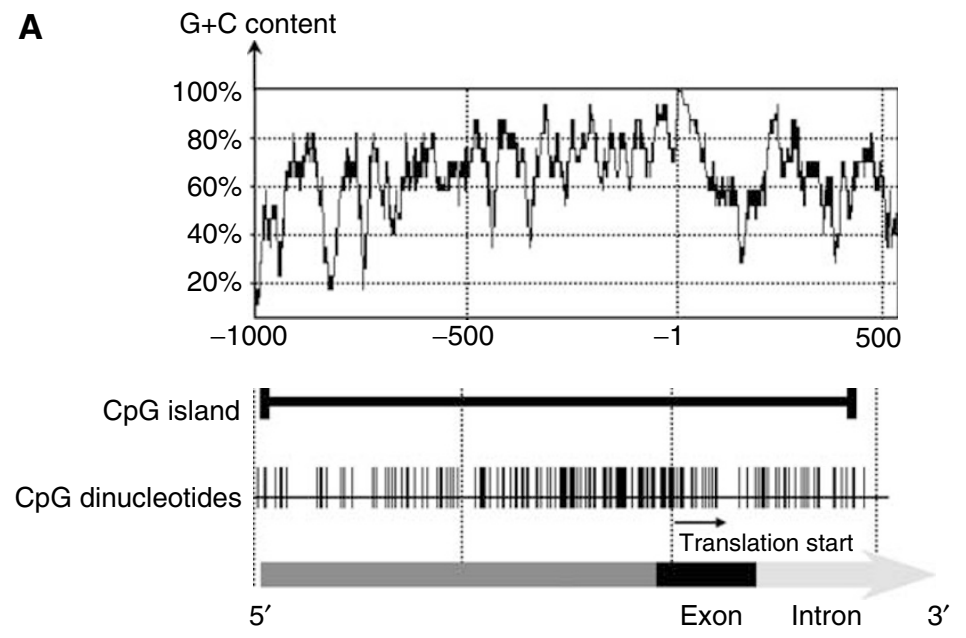

B GRAF promoter fragments

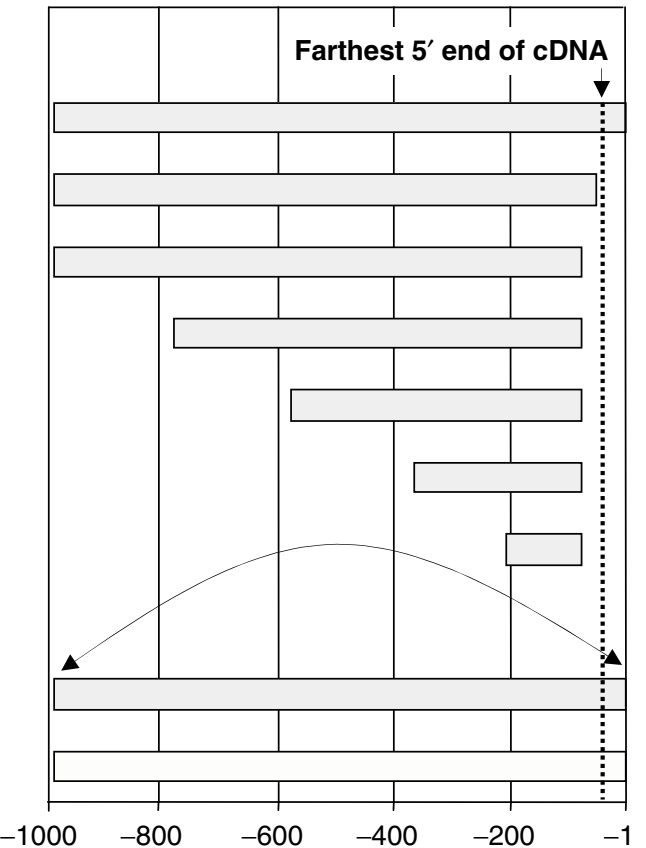

(bp) upstream ATG

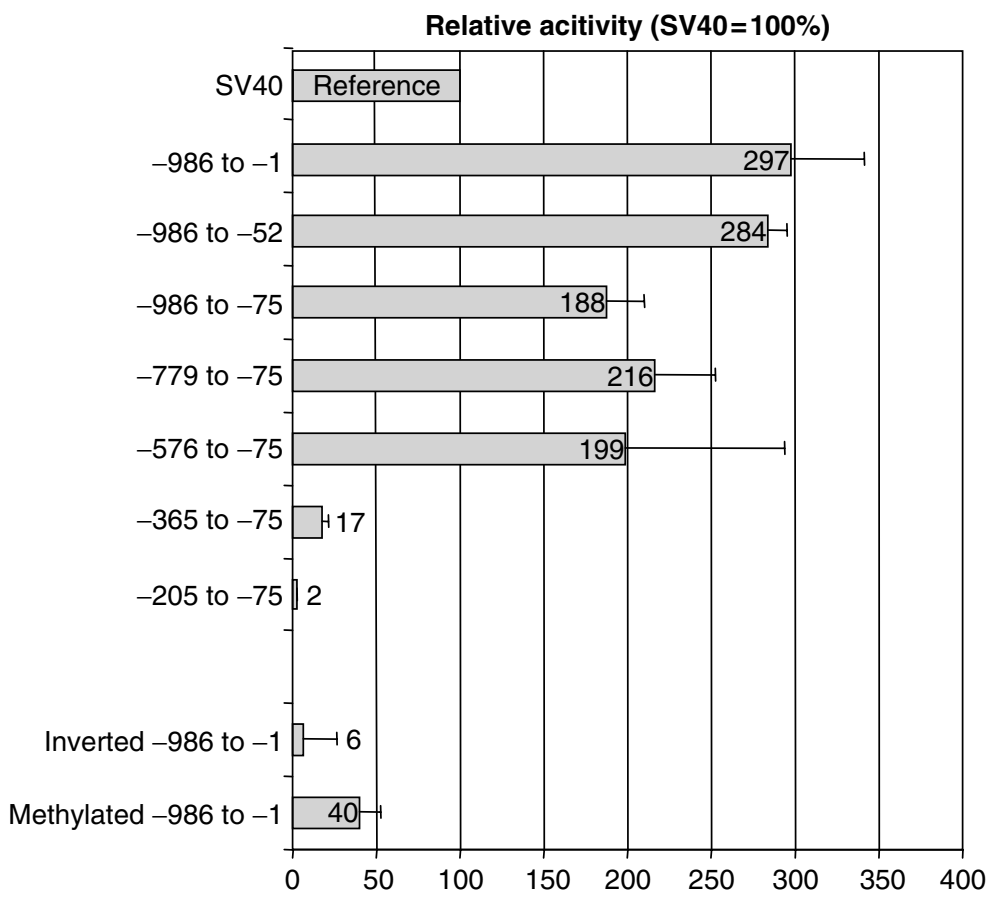

(\%)

Figure I Overview $(\mathbf{A})$ and deletion analyses (B) of the GRAF promoter. (A) The GRAF promoter is a GC-rich area with a dense concentration of CpG dinucleotides and a CpG island extending from $-98 \mathrm{I}$ in the promoter to +350 in the downstream intron (numbering of nucleotides relative to $\mathrm{A}(=+\mathrm{I}$ ) in the START-ATG codon). Segment -986 to - I was examined with reporter gene assays. (B) Left panel: The promoter segments (numbering relative to A $(=+1)$ in the START-ATG codon). Right panel: Relative firefly luciferase activity normalised against the promoting activity of SV40 (= I00\%). K562 cells were transiently transfected with a pGL3 plasmid containing different segments of the GRAF promoter. Inversion (arrow) or methylation of the promoter completely abolishes any promoting activity. The data represent the mean \pm s.d. of three independent experiments.

30000 c.p.m. of DNA were incubated in binding buffer (Nickel et al, 1995) supplemented with $1 \mu \mathrm{g}$ of $\mathrm{dIdC}$ and various amounts of nuclear extracts as indicated in the figures. Subsequently, a DNase I digest was performed in a total volume of $60 \mu \mathrm{l}$ for $10 \mathrm{~min}$ on ice or at room temperature. The chosen incubation conditions only allowed an incomplete digestion, leaving a specific population of partially digested promoter fragments. The reaction was terminated by adding 2 volumes of stop buffer and $30 \mu \mathrm{g}$ of proteinase $\mathrm{K}$ and incubation at $55^{\circ} \mathrm{C}$ for $30 \mathrm{~min}$. The promoter fragments were extracted and subjected to electrophoresis on a $6 \%$ polyacrylamide, $8 \mathrm{M}$ urea gel, thereby separating the partially digested DNA fragments according to size. A G + A ladder served as a marker of size. Finally, the dried gel was autoradiographed on an X-ray film.

Nuclear proteins binding to the DNA could decrease the accessibility of the DNA for DNase I, thus leading to regions on the DNA protected from digestion. The binding could also induce conformational changes of the DNA, increasing the accessibility of the DNA for nucleases and leading to hypersensitive sites. Accordingly, DNase I protection/hypersensitivity is assumed to represent protein binding to the promoter fragment and is recognised as a change in the migration pattern from the lane without nuclear extract to the lanes with nuclear extract. In an attempt to quantify the effect, we used increasing amounts of 
DNase I or nuclear extract. If methylation of the promoter fragment is able to abolish this change of migration from the lane without nuclear extract to the lanes with nuclear extract, we interpret this as abolishment of protein binding.

\section{Quantification of GRAF mRNA by real-time PCR}

For the quantification of the GRAF mRNA, a TaqMan ${ }^{\mathrm{TM}}$ PCR assay in combination with an ABI PRISM ${ }^{\mathrm{TM}} 7700$ Sequence Detector (Applied Biosystems, Foster City, CA, USA) was used. After isolation of total RNA with Trizol ${ }^{\mathrm{TM}}$ reagent (Invitrogen, Karlsruhe, Germany), reverse transcription of $1 \mu \mathrm{g}$ of RNA was performed using Superscript II reverse transcriptase (Invitrogen, Karlsruhe, Germany) and oligo-dT primers (Sigma, Schnelldorf, Germany) according to the manufacturer's recommendations. A $1 \mu$ l portion of this cDNA served as template in a $25 \mu \mathrm{l}$ two-step qPCR reaction (conditions are available upon request; for primer and probe sequences, see Table 1, PCR product: $81 \mathrm{bp}$ ). Each PCR was performed in triplicate and the number of GRAF mRNA molecules was determined according to a standard curve generated by a plasmid dilution series and normalised to the number of $A B L$ mRNA molecules in a corresponding preparation.

\section{Patients' samples}

Bone marrow samples from 29 paediatric patients suffering from AML or MDS were collected in the framework of the BerlinFrankfurt-Muenster (BFM) study group. The selection of cases was biased with regard to availability of frozen tumour material as a prerequisite for the analysis. All samples were sent by mail to the Oncogenetic Laboratory of the Children's University Hospital in Giessen, Germany. We were not aware of any differences in tissue processing among the 29 samples studied. The mononuclear cells were separated by Ficoll ${ }^{\mathrm{B}}$ density gradient centrifugation according to the manufacturer's instructions (Serva, Heidelberg, Germany). The cells were resuspended in $250 \mu$ l PBS, shock frozen in liquid nitrogen and stored at $-80^{\circ} \mathrm{C}$ until analyses.

\section{Methylation-sensitive PCR}

The MS-PCR was performed basically as described by Herman et al (1996). In brief, $1 \mu \mathrm{g}$ genomic DNA in a volume of $70 \mu \mathrm{l}$ was denatured by $\mathrm{NaOH}$ treatment (final concentration $0.33 \mathrm{M}$ ) for $15 \mathrm{~min}$ at $37^{\circ} \mathrm{C}, 3 \mathrm{~min}$ at $95^{\circ} \mathrm{C}$ and $30 \mathrm{~min}$ at $80^{\circ} \mathrm{C}$. Modification of unmethylated cytosine residues was performed by adding $1 \mathrm{ml}$ of
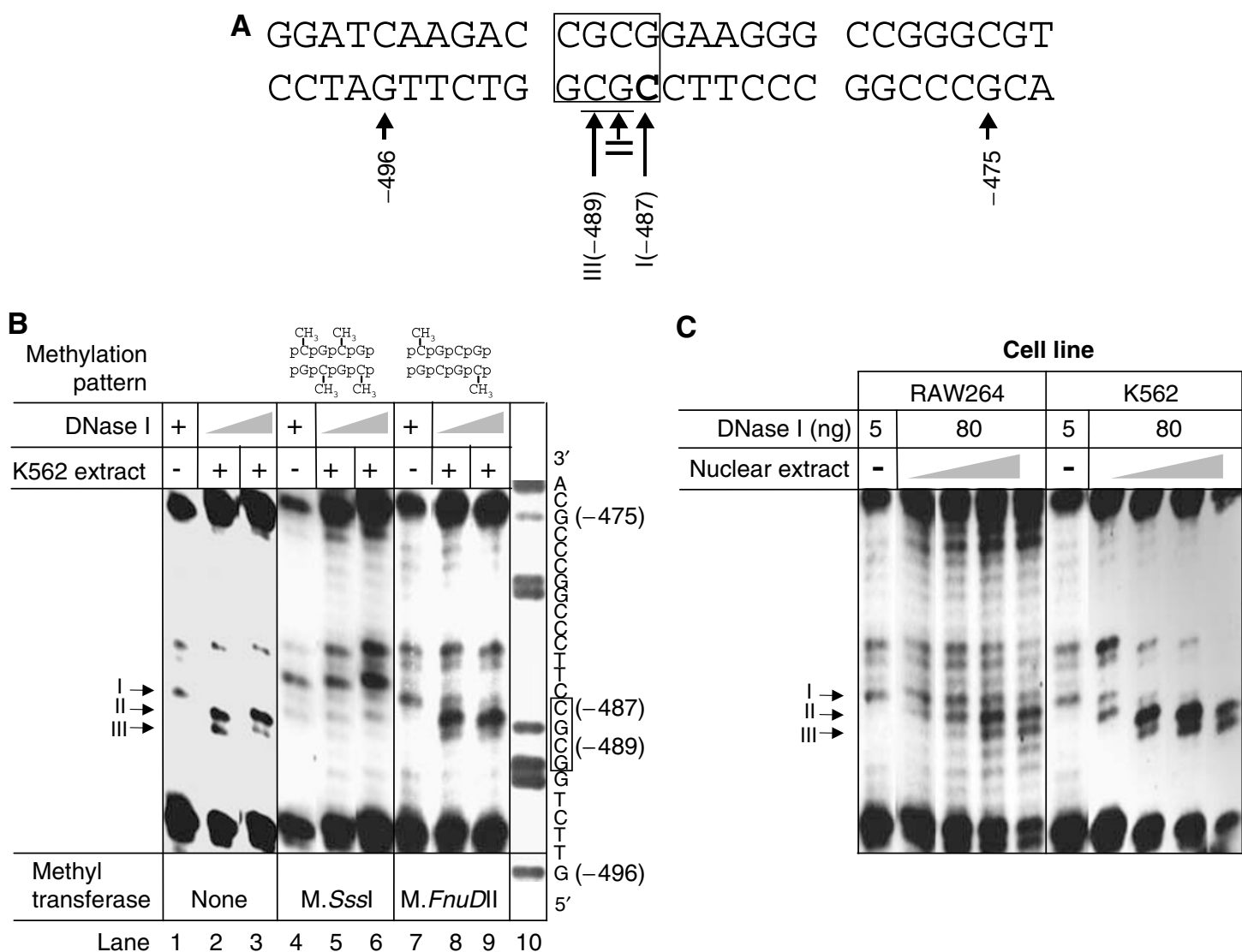

Figure 2 Footprint I site (Fp I). (A) Sequence of the footprint I site. The ciphers I, II and III correspond to the footprinting positions from the DNase I protection assay. The DNase I-protected position is shown in bold and DNase I-hypersensitive positions are underlined. The recognition sequence of M.FnuDII is boxed. (B) DNase I protection assays. Methylation of the promoter fragment modifies binding of nuclear extract proteins to footprint I site. Compared to the promoter fragments partially digested by DNase I alone (lane I), addition of nuclear extracts $(90 \mu \mathrm{g})$ from K562 cells changed the digestion pattern. While one signal (I) is reduced, the intensity of two other bands is increased (II and III). M.Sssl methylates every cytosine residue in a CpG dinucleotide, and this methylation abolishes binding of trans-acting factors (lanes 4-6 are essentially identical). M.FnuDll only methylates the lateral cytosin residues in a CpG tetranucleotide and apparently this hemimethylation does not inhibit protective binding of trans-acting factors (lanes 7-9 are essentially identical to lanes I-3). The A + G ladder (lane 10) shows the reverse complementary sequence. Numbers refer to positions relative to A in the STARTATG $(=+1)$; the M.FnuDII recognition sequence is boxed. $(\mathbf{C})$ DNase I protection assays: The binding of the trans-acting factors is not cell specific. DNase I protection assay with increasing amounts (20,50,90 and I20 $\mathrm{gg}$ ) of nuclear extracts. Band I loses intensity as the amount of nuclear extracts is increased, whereas bands II and III gain intensity. Thus, band I is protected by protein binding and bands II and III are hypersensitive to DNase digestion by protein binding, regardless of the source of the nuclear extract. 
$3 \mathrm{M} \mathrm{NaSO}_{3}$ (Sigma, Schnelldorf, Germany) prewarmed at $55^{\circ} \mathrm{C}$ and incubation under mineral oil for $4 \mathrm{~h}$ in the dark at $55^{\circ} \mathrm{C}$. Subsequently, the modified DNA was purified using the Geneclean Kit (Bio 101, Vista, CA, USA). DNA was resuspended in $20 \mu \mathrm{l} \mathrm{H}_{2} \mathrm{O}$ and used immediately or stored at $-20^{\circ} \mathrm{C}$.

PCR was performed as a nested hot-start PCR (conditions available upon request) with the primers listed in Table 1.

In parallel, for each MS-PCR, appropriate PCR controls using unmethylated (negative control) and in vitro-methylated genomic DNA (positive control) isolated from a healthy volunteer were performed.

The MS-PCR products (126 bp) were visualised on a $2 \%$ agarose gel and sequenced.

\section{RESULTS}

\section{Isolation and characterisation of the $5^{\prime}$ flanking region of} GRAF

Multiple $5^{\prime}$ RACE-PCR products were sequenced and the $5^{\prime}$ farthest cDNA fragment began only $37 \mathrm{bp}$ upstream of the first ATG codon (GenBank accession no. Y10388). Next, we isolated a sequence of $3080 \mathrm{bp}$ upstream of the presumed translation initiation codon by genome walking (GenBank accession no. AF196313).

A CpG island/HTF (HpaII tiny fragment) according to the definition of Gardiner-Garden and Frommer (1987) spanning the first $981 \mathrm{bp}$ immediately upstream of the presumed translation initiation codon, an exon and the first $350 \mathrm{bp}$ of the adjacent intron was identified (Figure 1A). We did not find a TATA box or other well-known transcription initiation signals.
Next, we performed reporter gene assays with a series of $5^{\prime}$ - and $3^{\prime}$-deleted GRAF promoter constructs generated by inserting PCR products into the pGL3-Basic vector just upstream of the firefly luciferase gene. The intact $5^{\prime}$ flanking region of $G R A F$ is a powerful promoter in K562 cells with about three times the activity of the SV40 promoter (Figure 1B). Deletion experiments demonstrated that the $5^{\prime}$ end of the region examined is of minor importance for the promoter activity. The smallest fragment with intact activity proved to be the -576 to -365 fragment (data not shown). Further $5^{\prime}$ deletions abolished the activity. The activity of the reversed segment -981 to -1 proved to be approximately $1 / 50$ of that of the unreversed segment. Thus, the promoter activity of the $5^{\prime}$ flanking $981 \mathrm{bp}$ is dependent upon direction. CpG methylation with the M.SssI methylase diminished the activity of the -981 to -1 fragment to approximately $1 / 7$ of the activity of the unmethylated construct, which suggests that binding of trans-acting factors might be dependent upon DNA demethylation. We therefore tried to identify these sites using DNase I protection assays.

In vitro DNase I protection assays revealed a putative proteinbinding site from position -475 to -496 (Fpl; Figure 2), which was apparent from the changes in the DNase I restriction pattern on adding nuclear extract (Figure 2B, lane 1 vs lanes $2+3$ ). This protein DNA interaction proved to be methylation sensitive, as methylating the DNA by using M.SssI abolished the interaction (Figure 2B, lane $4 v s$ lanes $5+6$ ). However, hemimethylating the DNA with M.FnuDII failed to prevent protein loading to the DNA (Figure 2B, lane 7 s lanes $8+9$ ).

Next, we checked whether protein loading to the GRAF promoter is cell type specific. However, we did not detect any difference in the DNase I restriction pattern when performing
A

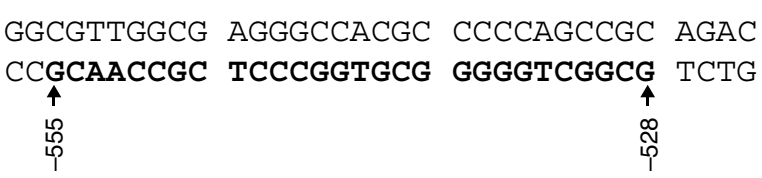

B

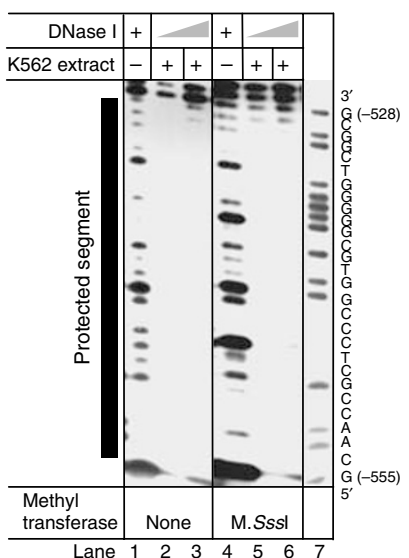

c

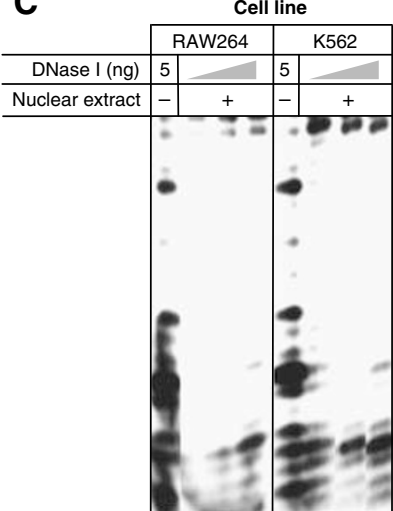

D
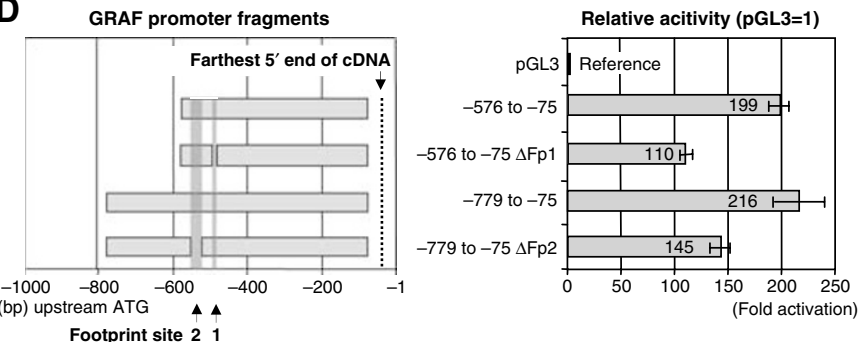

E

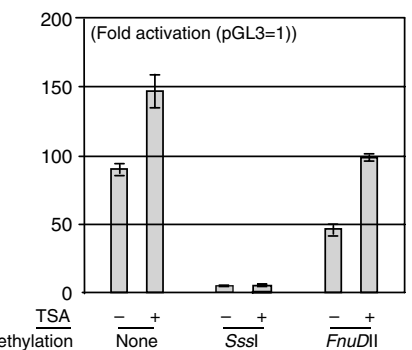

Figure 3 Footprint 2 site (Fp2). (A) Sequence of the footprint 2 site (Fp2). The sequence marked with bold is protected from DNase I digestion by binding of trans-acting factors. (B) DNase I protection assays: The segment - 555 to - 528 is protected from DNase I digestion (lanes 2 and 5: 40 ng; lanes 3 and 6: $80 \mathrm{ng}$ DNase I) by binding of trans-acting factors from nuclear extract from K562 cells ( $90 \mu \mathrm{g})$. This binding is insensitive to M.Sssl methylation of the DNA, as the DNA methylation does not alter the restriction pattern. The protected segment is marked by the black bar. The A $+\mathrm{G}$ ladder (lane 7 ) shows the reverse complementary sequence. Numbers refer to positions relative to $\mathrm{A}$ in the START-ATG $(=+1)$. (C) The interaction of proteins with the Fp2 region of the GRAF promoter is not cell specific. Nuclear extracts from both RAW264 and K562 cells ( $90 \mu \mathrm{g})$ can protect unmethylated DNA from digestion with increasing amounts of DNase I (40, 80 and I $80 \mu \mathrm{g})$. (D) Deletion of the footprint sites Fp I and Fp2 reduces the promoter activity. Left panel: The promoter segments (numbering relative to $\mathrm{A}(=+\mathrm{I})$ in the START-ATG codon). Right panel: Relative luciferase activity normalised against the promoting activity of the empty pGL3 plasmid $(=1)$. The data represent the mean \pm s.d. of three independent experiments. (E) Promoting repression by the M.FnuDII hemimethylation is partially reversible by incubation with the histone deacetylase inhibitor TSA, whereas CpG methylation with M.Sssl causes a complete block of the promoting activity, which cannot be restored by incubation with TSA. The reporter activities are shown as folds of increase of luciferase activity compared to the empty pGL3 plasmid. The data represent the mean \pm s.d. of three independent experiments. 
protection assays in the presence of nuclear extracts prepared from either K562 or RAW264 cells, a mouse macrophage cell line (Figure 2C).

A second putative binding site, footprint site (Fp2), was identified (Figure 3). For Fp2 however, protein binding was not methylation sensitive (Figure $3 \mathrm{~B}$ ) and, as for $\mathrm{Fp} 1$, the protein loading was not cell type specific (Figure 3C).

Confirmatory deletions of the two putative protein-binding sites from the promoter reduced the promoting activities in dual luciferase reporter assays (Figure 3D). Dual luciferase reporter assays with unmethylated and M.FnuDII- or M.SssI-methylated promoter constructs demonstrated methylation sensitivity of the promoter. Thus, pGL3 constructs containing an unmethylated GRAF promoter showed higher relative activity than M.FnuDIImethylated constructs, which had a higher relative activity than the completely methylated M.SssI constructs. The relative activity of the M.FnuDII-methylated constructs could be partially restored by incubating the cells with an inhibitor of histone deacetylase, TSA. However, TSA could not restore the activity of the fragments completely methylated by M.SssI (Figure 3E).

\section{Influence of chromatin modifications on GRAF expression}

To test the influence of a demethylating agent on the GRAF expression in five leukaemia and lymphoma cell lines, they were treated with 5-azadC during at least one replication cycle. 5-Aza2 -deoxycytidine is a nucleotide analogue inhibiting DNA methyltransferase 1 , which has to be incorporated into newly synthesised DNA. An integration rate of $0.3 \%$ is sufficient to inhibit $95 \%$ of methyltransferases (Creusot et al, 1982), as the enzymes become covalently bound to 5 -azadC. The subsequent demethylation of the DNA leads to an activation of genes previously inactivated by methylation (Juttermann et al, 1994). Quantitative PCR analyses of 5 -azadC-treated cells $v s$ untreated cells revealed an increase of GRAF expression in Mutz-1 and K562 and a highly significant increase in the AML cell line Kasumi-1 (Figure 4A). Morphologically, we did not notice any changes (data not shown).

To test the influence of the histone deacetylase inhibitor TSA, five leukaemia and lymphoma cell lines were treated with $100-$ $300 \mathrm{ng}$ TSA per ml culture medium for $16 \mathrm{~h}$. Quantitative PCR showed an enhanced GRAF expression in all cell lines examined, but the TSA concentration necessary to achieve this effect varied. In the myeloid cell line Mutz-1, $100 \mathrm{ng} \mathrm{ml}^{-1}$ TSA had no effect, whereas 200 and $300 \mathrm{ng} \mathrm{ml}^{-1}$ TSA elevated the GRAF expression level two- and three-fold $v s$ the untreated controls. In Kasumi-1 and $\mathrm{K} 562,300 \mathrm{ng} \mathrm{ml}^{-1}$ was necessary to double the GRAF expression. In contrast, treating the Jurkat (derived from T-cell leukaemia lymphoma) and Daudi (lymphoma) cell lines with $100 \mathrm{ng} \mathrm{ml}^{-1}$ TSA elevated the GRAF expression four- and sevenfold compared to the untreated controls (Figure 4B). The influence

\section{A}

GRAF expression + 5-azadC

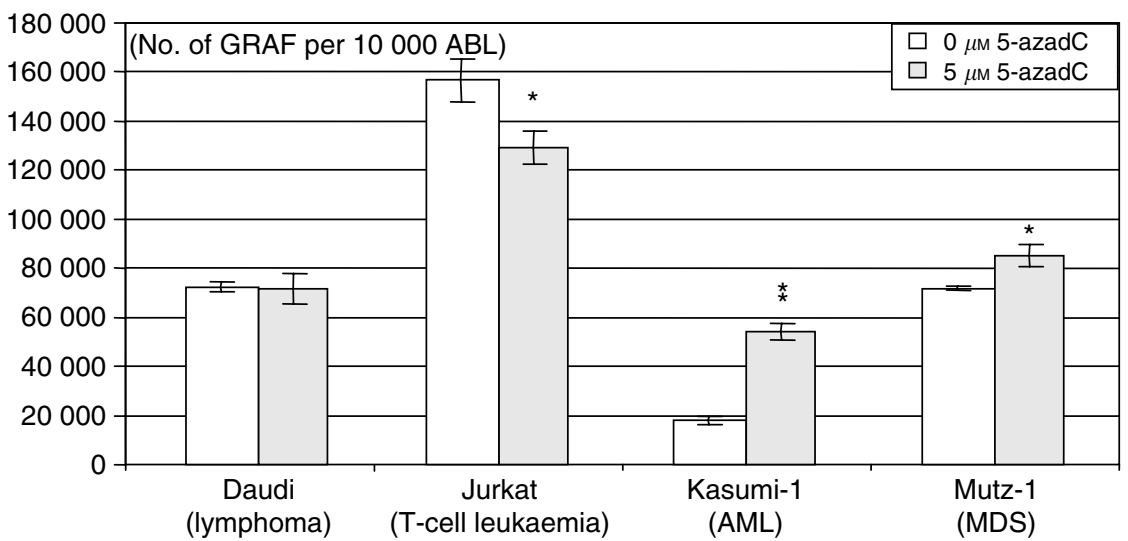

B

\section{GRAF expression + TSA}

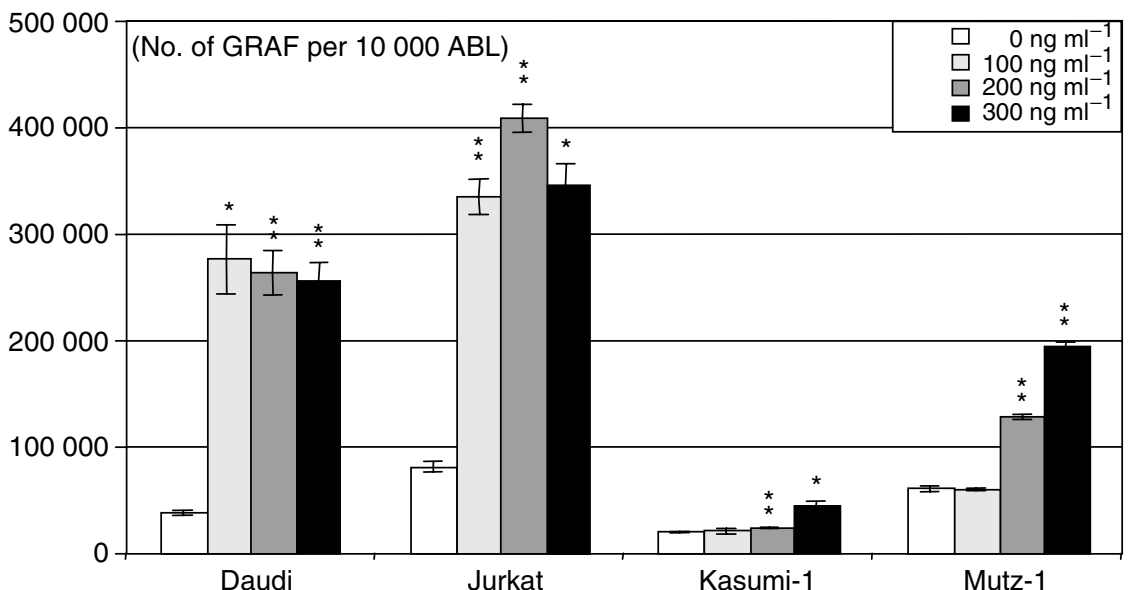

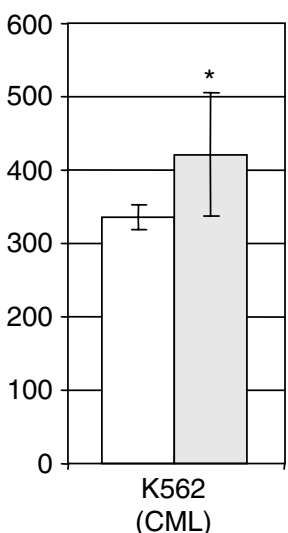

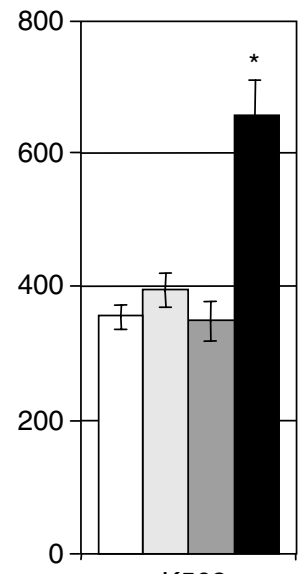

K562

Figure 4 GRAF expression levels in cell lines after treatment with 5-azadC and TSA. (A) Expression levels of GRAF analysed by quantitative RT-PCR relative to a housekeeping gene (ABL) in cells treated with $5 \mu \mathrm{M} 5$-azadC for $72 \mathrm{~h}$ vs untreated controls. $* P<0.05$; $* * * 0.005$ ( $\mathrm{t}$-test of untreated vs treated). The data represent the mean \pm s.d. of three independent experiments. (B) Expression levels of GRAF by quantitative RT-PCR relative to a housekeeping gene (ABL) in cells treated with $0-300 \mathrm{ng}$ TSA per $\mathrm{ml}$ culture medium for $16 \mathrm{~h}$. $* P<0.05$; $* * P<0.005$ ( $t$-test of untreated vs treated). The data represent the mean \pm s.d. of three independent experiments. 
A

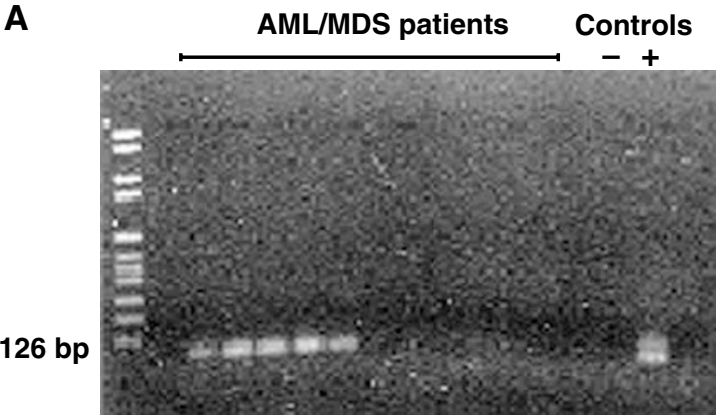

B

\begin{tabular}{|c|c|c|c|c|c|c|}
\hline GP & cgtcctcggg & cggcctgagg gtdgggcagg & ggagggtgcg & ctgattggcc & cggcggggat... & \\
\hline UP & cgtttttggg & tggtttgagg gttlgggtagg & ggagggtgtg & ttgattggtt & tggtggggat... & \\
\hline MP & cgttttcggg & cggtttgagg gtogggtagg & ggagggtgcg & ttgattggtt & cggcggggat... & \\
\hline 2 & cettttccgg & ccgtttgagg & ggagggtgcg & ttgattggtt & ggcggggat... & \\
\hline 3 & cettetccgg & ccgtttgagg & ggagggtgcg & ttgattggtt & ggcggggat... & \\
\hline 4 & cottttcogg & ccgtttgagg & ggagggtgcg & ttgattggtt & cggcggggat... & \\
\hline 5 & cetttecgg & ccgtttgagg gtogggtagg & ggagggtgcg & ttgattggtt & cggcggggat... & \\
\hline 6 & cctttecgg & ccgtttgagg gtogggtagg & ggagggtgcg & ttgattggtt & cggcggggat... & \\
\hline 15 & 5 cetttecgg & ccgtttgagg gtolgggcagg & ggagggtgcg & ttgattggtt & cggcggggat... & \\
\hline osition - & -475 & -455 & & -435 & & \\
\hline GP & ?...taagtcatcg & ctagcaggtt cgagcggccc & agacaccggc & gggg $\longdiv { \operatorname { c g g c c g } }$ & aggctgctgt & gagagg \\
\hline UP & ...taagttattg & ttagtaggtt & agatattggt & ggggtggttg & gttgt & gagg \\
\hline MP & ...taagttatcg & ttagtaggtt cgagcggttt & agatatcggc & ggggleggtcg & aggttgttgt & gagagg \\
\hline 2 & ...taagttatcg & ttagtaggtt & agatatcggc & gggglcggtcg & ttgttgt & agg \\
\hline 3 & ...taagttatcg & ttagtaggtt & gatatcggc & ggggleggtcg & tgttgt & gagagg \\
\hline 4 & ...taagttatcg & ttagtaggtt & ggc & gggglcggtcg & tgttgt & gagagg \\
\hline 5 & ...taagttatcg & ttagtaggtt & $\operatorname{tcggc}$ & gggglcggtcg & ctgttgt & gagagg \\
\hline 6 & ...taagttattg & ttagcaggtt & gatatcggc & gggglcggtcg & aggttgttgt & gagagg \\
\hline 15 & 5 ...taagttgtcg & ttagtaggtt $c \subseteq$ & & ggggleggtcg & aggttgttgt & gagagg \\
\hline Position - & -415 & -395 & & -375 & & -355 \\
\hline
\end{tabular}

Figure 5 Methylation-sensitive PCR of the GRAF promoter in patients' samples. (A) Methylation-sensitive PCR. A I26 bp fragment of the GRAF promoter (segment -475 to -350) was amplified by applying MS-PCR. An artificially M.Sssl-methylated promoter construct served as a positive control. (B) Sequences of MS-PCR products. Alignment of six PCR products ( -475 to -350$)$ generated from patient samples showing complete methylation of CpG dinucleotides within the GRAF promoter. Numbering refers to patients in Table 2. GP=germline promoter sequence; UP = unmethylated promoter sequence after MS-PCR; MP = methylated promoter after MS-PCR. Bold cytosine and guanine residues indicate sequence variations and inverted thymidine residues indicate a lack of methylation. Primer sequences are framed.

of a combination of TSA and 5-azadC on GRAF expression levels has not been tested.

\section{CpG methylation of the GRAF promoter in patients with AML/MDS}

Methylation-sensitive PCR was used to reveal the presence of a deactivating $\mathrm{CpG}$ methylation in the $5^{\prime}$ flanking region. Bone marrow and peripheral blood from 37 healthy donors and bone marrow samples from 29 patients with AML or MDS were analysed by MS-PCR and sequencing of the MS-PCR-positive products. Among the healthy individuals, only one out of 37 showed a positive MS-PCR (2.7\%). The sequence of this PCR product revealed methylation of the cytosine residues at the primer-binding sites but not within the PCR product. We therefore interpret this as a technical error. In 11 out of 29 patient samples (38\%), a PCR product was generated, indicating a methylated GRAF promoter (Figure $5 \AA$ and Table 2). Six PCR products were sequenced showing a complete methylation of the cytosine residue in $\mathrm{CpG}$ dinucleotides (Figure 5B). Unfortunately, lack of sufficient patient material prevented us from testing the GRAF protein expression by immunohistochemical analysis or to correlate GRAF methylation status with GRAF expression.

\section{DISCUSSION}

The GRAF gene located at chromosome $5 \mathrm{q} 31$ is a rare fusion partner of $M L L$ in cases of AML. So far, the fusion has been reported in only three cases, all resulting in similar clinical features (Borkhardt et al, 2000; Panagopoulos et al, 2004; Wilda et al, 2005). In the present study, we identify and characterise the regulative region of the GRAF gene. The GRAF promoter lacks a TATA or CCAAT box, but the transcription initiation site is flanked by a CpG island as described for other genes (Gardiner-Garden and Frommer, 1987).

CpG islands are well-known targets of epigenetic modifications. Methylation of cytosine residues is responsible for silencing of transposable elements, for defence against viral sequences and for the transcriptional repression of genes. The methylation status is heritable through cell divisions and maintained by a number of DNA methyltransferases (Egger et al, 2004).

To address the question whether GRAF expression might be compromised by other mechanisms in patients without $M L L$ GRAF fusion, we examined bone marrow samples from patients with AML or MDS. In previous studies, three out of 13 samples with loss of one $5 \mathrm{q}$ allele exhibited a disruption of the second GRAF allele by insertions (Borkhardt et al, 2000). Therefore, if $G R A F$ has tumour-suppressing abilities, we assume that additional mutations or epigenetic modifications contribute to the malignant 
Table 2 Results of the MS-PCR

\begin{tabular}{|c|c|c|}
\hline Sample & Diagnosis, subtype & MS-PCR result \\
\hline I & AML, M7 & - \\
\hline 2 & AML, not classified & + \\
\hline 3 & AML, M5 & + \\
\hline 4 & AML, M5 & + \\
\hline 5 & AML, M5 & + \\
\hline 6 & AML, not classified & + \\
\hline 7 & AML, M5 & - \\
\hline 8 & AML, M4 & - \\
\hline 9 & AML, M4 & - \\
\hline 10 & AML, M2 & - \\
\hline 11 & AML, M2 & - \\
\hline 12 & AML, M2 & - \\
\hline 13 & AML, M2 & - \\
\hline 14 & AML, M2 & - \\
\hline 15 & AML, M2 & + \\
\hline 16 & MDS, JMML & + \\
\hline 17 & MDS, RAEB-T, ANLL & + \\
\hline 18 & MDS, RA & - \\
\hline 19 & MDS, RA & - \\
\hline 20 & MDS, CMML & - \\
\hline 21 & MDS, CMML & + \\
\hline 22 & MDS, not classified & - \\
\hline 23 & MDS, CMML & + \\
\hline 24 & MDS, not classified & + \\
\hline 25 & MDS, RAEB & - \\
\hline 26 & MDS, RA & - \\
\hline 27 & MDS, RA & - \\
\hline 28 & MDS, RAEB & - \\
\hline 29 & MDS, not classified & - \\
\hline
\end{tabular}

MS-PCR = methylation-sensitive PCR; AML = acute myeloid leukaemia; $M D S=$ myelodysplastic syndrome.

phenotype by downregulation or complete abolishment of GRAF expression. The involvement of epigenetic modifications such as promoter methylation is well known for a variety of established tumour suppressor genes, the most prominent examples being the retinoblastoma gene product and the cyclindependent kinase inhibitor CDKN2A. For both genes, dense hypermethylation of the promoter leads to a loss of gene expression (Herman, 1999). Likewise, epigenetic events (hypermethylation) in the genes $h M L H 1$, p16INK4A and GSTPI can also lead indirectly to tumour progression by promoting genetic instability in several tumour entities, such as breast, prostate, gastric or colon cancer (Baylin and Herman, 2000; Herman and Baylin, 2003). Along these lines we show a repression of activity owing to methylation of the GRAF promoter. Two areas with special importance for the activity of the promoter have been identified and examined by DNase I protection assays (footprint sites Fp1 and Fp2). These in vitro assays indicated the binding of two factors to the GRAF promoter. Presumably, both factors are not expressed in a cell-specific manner. The Fp1 region contains three CpG dinucleotides of which an incomplete methylation by M.FnuDII did not interfere with the binding of the protein factor. Only complete methylation by M.SssI abolished the binding, indicating an interference of the methylated $3^{\prime}$ cytosine within the methylase recognition site (CGCG) with the DNA binding of the protein. Thus, the interaction of the protein with Fp1 is methylation sensitive, as has been found for a variety of transcription factors such as CREB, NF- $\kappa \mathrm{B}, \mathrm{E} 2 \mathrm{~F}$ or AP2 (Kovesdi et al, 1987; Iguchi-Ariga and Schaffner, 1989; Comb and Goodman, 1990; Bednarik et al, 1991; Baylin and Herman, 2000; Herman and Baylin, 2003).

A second factor interacts with footprint site 2 (Fp2) but without exhibiting methylation sensitivity. Similar behaviour has been demonstrated for the transcription factors CTF and YY1 (Ben Hattar et al, 1989; Gaston and Fried, 1995). Nevertheless, it is possible that modifications of the chromatin structure as a consequence of the DNA methylation block the binding of a protein factor in vivo although the factor is methylation insensitive in vitro, as is known for NF-Y (Ammerpohl et al, 1997, 1998). As our attempt to identify both binding factors by yeast one-hybrid assays failed, these important transcriptional regulators have to be identified in further studies.

Methylation of the GRAF promoter in patients with AML or MDS was examined by MS-PCR, in which methylated and unmethylated alleles are distinguished by conversion of all unmethylated, but not of the methylated, cytosine to uracil residues with bisulphite (Herman et al, 1996). In 38\% of AML and MDS patients, we detected methylation of the GRAF promoter. Within a control group of 37 blood donors, only one incompletely methylated GRAF promoter was detectable (3\%), indicating a highly increased rate of GRAF promoter methylation in haematologic disorders of myeloid origin.

GRAF expression is also influenced by the histone acetylation status. Acetylation and deacetylation of nucleosomal histones are important cellular tools for the regulation of gene expression. Hyperacetylated histones are associated with gene activity whereas a lack of acetylation leads to the repression of gene expression (Marks et al, 2003). These epigenetic modifications are catalysed by two groups of enzymes, histone acetyl transferases and histone deacetylases (HDACs). Inhibition of HDACs is thought to augment gene transcription, as the histones cannot be changed to their highly condensed, hypoacetylated form (Kim et al, 2003). Application of TSA leads to an enhancement of GRAF expression, especially in the non-myeloid cell lines tested. The effect was dose dependent in the myeloid cell lines, which required at least twice as much TSA as the nonmyeloid cell lines, indicating an additional layer of modification regulating GRAF expression in these cells. Trichostatin A induces significant changes in gene expression in only $2 \%$ of all genes (Marks et al, 2001), so histone acetylation seems to play a specific role in the regulation of GRAF gene expression. The different developmental lines in haematological differentiation therefore seem to become manifest in different GRAF chromatin patterns. Histone deacetylase inhibitors are tested in clinical trials, as they are known to induce growth arrest, differentiation and/or apoptosis in cells of various tumour types (Marks et al, 2000, 2001).

It has been shown extensively by others that treatment of leukaemia cell lines employed in our work (Daudi, Jurkat, Kasumi-1, Mutz-1 and K562) with the HDAC inhibitor TSA or the DNA methyltransferase 1 inhibitor 5 -azadC has a profound impact on the expression of several genes and decreases proliferation and clonogenic survival and increases the level of apoptotic markers (Blagosklonny et al, 2002; Zhu and Otterson, 2003; Karagiannis et al, 2004; Liu et al, 2004; Yokota et al, 2004; Furukawa et al, 2005). Therefore, it is not surprising that the expression level of GRAF seems to be influenced as well. Our findings are consistent with the fact that treatment of cells with 5 -azadC leads to an enhancement of GRAF expression only in myeloid cells, especially in a cell line derived from an AML. However, additional work is necessary to characterise the nature of these interactions in more detail in myeloid leukaemia $v s$ MDS. Whether CpG methylation of the GRAF promoter and/or the GRAF expression level could improve the initial diagnosis, stratification or prognostication of patients with myeloproliferative diseases should be addressed in future studies including a large number of patients.

In conclusion, varying mechanisms (translocations, allelic loss, insertions, promoter methylation and probably chromatin modification) leading to an inactivation of GRAF can be observed in a subset of AML and MDS cases. The pathogenetic role of 
aberrant GRAF expression in these diseases remains to be established.

\section{ACKNOWLEDGEMENTS}

We thank Claudia Keller for excellent assistance. This work was in part supported by grants of the Deutsche Forschungsgesells- chaft (Bo 1549/2-1), Danish Medical Research Council (52-001148), The Novo Nordisk Foundation and the Forschungshilfe Station Peiper.

Supplementary Information accompanies the paper on British Journal of Cancer website (http://www.nature.com/bjc)

\section{REFERENCES}

Ammerpohl O, Schmitz A, Steinmüller L, Renkawitz R (1998) Repression of the mouse M-lysozyme gene involves both hindrance of enhancer factor binding to the methylated enhancer and histone deacetylation. Nucleic Acids Res 26: 5256-5260

Ammerpohl O, Short ML, Asbrand C, Schmitz A, Renkawitz R (1997) Complex protein binding to the mouse M-lysozyme gene downstream enhancer involves single-stranded DNA binding. Gene 200: $75-84$

Baylin SB, Herman JG (2000) DNA hypermethylation in tumorigenesis: epigenetics joins genetics. Trends Genet 16: $168-174$

Bednarik DP, Duckett C, Kim SU, Perez VL, Griffis K, Guenthner PC, Folks TM (1991) DNA CpG methylation inhibits binding of NF-kappa B proteins to the HIV- 1 long terminal repeat cognate DNA motifs. New Biol 3: $969-976$

Ben Hattar J, Beard P, Jiricny J (1989) Cytosine methylation in CTF and Sp1 recognition sites of an HSV tk promoter: effects on transcription in vivo and on factor binding in vitro. Nucleic Acids Res 17: 10179-10190

Blagosklonny MV, Robey R, Sackett DL, Du L, Traganos F, Darzynkiewicz Z, Fojo T, Bates SE (2002) Histone deacetylase inhibitors all induce p21 but differentially cause tubulin acetylation, mitotic arrest, and cytotoxicity. Mol Cancer Ther 1: 937-941

Borkhardt A, Bojesen S, Haas OA, Fuchs U, Bartelheimer D, Loncarevic IF, Bohle RM, Harbott J, Repp R, Jaeger U, Viehmann S, Henn T, Korth P, Scharr D, Lampert F (2000) The human GRAF gene is fused to MLL in a unique $\mathrm{t}(5 ; 11)(\mathrm{q} 31 ; \mathrm{q} 23)$ and both alleles are disrupted in three cases of myelodysplastic syndrome/acute myeloid leukemia with a deletion 5q. Proc Natl Acad Sci USA 97: 9168-9173

Comb M, Goodman HM (1990) CpG methylation inhibits proenkephalin gene expression and binding of the transcription factor AP-2. Nucleic Acids Res 18: 3975 - 3982

Creusot F, Acs G, Christman JK (1982) Inhibition of DNA methyltransferase and induction of Friend erythroleukemia cell differentiation by 5-azacytidine and 5-aza-2'-deoxycytidine. J Biol Chem 257: 2041 - 2048

Dignam JD, Lebovitz RM, Roeder RG (1983) Accurate transcription initiation by RNA polymerase II in a soluble extract from isolated mammalian nuclei. Nucleic Acids Res 11: 1475-1489

Dobrovic A, Simpfendorfer D (1997) Methylation of the BRCA1 gene in sporadic breast cancer. Cancer Res 57: $3347-3350$

Egger G, Liang G, Aparicio A, Jones PA (2004) Epigenetics in human disease and prospects for epigenetic therapy. Nature 429: 457-463

Furukawa Y, Sutheesophon K, Wada T, Nishimura M, Saito Y, Ishii H, Furukawa Y (2005) Methylation silencing of the Apaf-1 gene in acute leukemia. Mol Cancer Res 3: 325-334

Gardiner-Garden M, Frommer M (1987) CpG islands in vertebrate genomes. J Mol Biol 196: $261-282$

Gaston K, Fried M (1995) CpG methylation and the binding of YY1 and ETS proteins to the Surf-1/Surf-2 bidirectional promoter. Gene 157: $257-259$

Gonzalez-Zulueta M, Bender CM, Yang AS, Nguyen T, Beart RW, Van Tornout JM, Jones PA (1995) Methylation of the $5^{\prime}$ CpG island of the p16/ CDKN2 tumor suppressor gene in normal and transformed human tissues correlates with gene silencing. Cancer Res 55: 4531-4535

Graff JR, Herman JG, Myohanen S, Baylin SB, Vertino PM (1997) Mapping patterns of $\mathrm{CpG}$ island methylation in normal and neoplastic cells implicates both upstream and downstream regions in de novo methylation. J Biol Chem 272: 22322-22329

Herman JG (1999) Hypermethylation of tumor suppressor genes in cancer. Semin Cancer Biol 9: 359-367

Herman JG, Baylin SB (2003) Gene silencing in cancer in association with promoter hypermethylation. N Engl J Med 349: 2042 - 2054

Herman JG, Graff JR, Myohanen S, Nelkin BD, Baylin SB (1996) Methylation-specific PCR: a novel PCR assay for methylation status of CpG islands. Proc Natl Acad Sci USA 93: $9821-9826$
Herman JG, Latif F, Weng Y, Lerman MI, Zbar B, Liu S, Samid D, Duan DS, Gnarra JR, Linehan WM (1994) Silencing of the VHL tumor-suppressor gene by DNA methylation in renal carcinoma. Proc Natl Acad Sci USA 91: $9700-9704$

Herman JG, Umar A, Polyak K, Graff JR, Ahuja N, Issa JP, Markowitz S, Willson JK, Hamilton SR, Kinzler KW, Kane MF, Kolodner RD, Vogelstein B, Kunkel TA, Baylin SB (1998) Incidence and functional consequences of hMLH1 promoter hypermethylation in colorectal carcinoma. Proc Natl Acad Sci USA 95: 6870-6875

Hildebrand JD, Taylor JM, Parsons JT (1996) An SH3 domain-containing GTPase-activating protein for Rho and $\mathrm{Cdc} 42$ associates with focal adhesion kinase. Mol Cell Biol 16: 3169-3178

Iguchi-Ariga SM, Schaffner W (1989) CpG methylation of the cAMPresponsive enhancer/promoter sequence TGACGTCA abolishes specific factor binding as well as transcriptional activation. Genes Dev 3: 612-619

Jarrard DF, Bova GS, Ewing CM, Pin SS, Nguyen SH, Baylin SB, Cairns P, Sidransky D, Herman JG, Isaacs WB (1997) Deletional, mutational, and methylation analyses of CDKN2 (p16/MTS1) in primary and metastatic prostate cancer. Genes Chromosomes Cancer 19: $90-96$

Juttermann R, Li E, Jaenisch R (1994) Toxicity of 5-aza-2'-deoxycytidine to mammalian cells is mediated primarily by covalent trapping of DNA methyltransferase rather than DNA demethylation. Proc Natl Acad Sci USA 91: $11797-11801$

Karagiannis TC, Smith AJ, El OA (2004) Radio- and chemo-sensitization of human erythroleukemic K562 cells by the histone deacetylase inhibitor trichostatin A. Hell J Nucl Med 7: 184-191

Kim DH, Kim M, Kwon HJ (2003) Histone deacetylase in carcinogenesis and its inhibitors as anti-cancer agents. J Biochem Mol Biol 36: 110-119

Kovesdi I, Reichel R, Nevins JR (1987) Role of an adenovirus E2 promoter binding factor in E1A-mediated coordinate gene control. Proc Natl Acad Sci USA 84: $2180-2184$

Liu ZJ, Zhang XB, Zhang Y, Yang X (2004) Progesterone receptor gene inactivation and $\mathrm{CpG}$ island hypermethylation in human leukemia cancer cells. FEBS Lett 567: $327-332$

Marks PA, Miller T, Richon VM (2003) Histone deacetylases. Curr Opin Pharmacol 3: $344-351$

Marks PA, Richon VM, Breslow R, Rifkind RA (2001) Histone deacetylase inhibitors as new cancer drugs. Curr Opin Oncol 13: 477-483

Marks PA, Richon VM, Rifkind RA (2000) Histone deacetylase inhibitors: inducers of differentiation or apoptosis of transformed cells. J Natl Cancer Inst 92: 1210-1216

Melki JR, Vincent PC, Clark SJ (1999) Concurrent DNA hypermethylation of multiple genes in acute myeloid leukemia. Cancer Res 59: $3730-3740$

Nickel J, Short ML, Schmitz A, Eggert M, Renkawitz R (1995) Methylation of the mouse M-lysozyme downstream enhancer inhibits heterotetrameric GABP binding. Nucleic Acids Res 23: 4785-4792

Ohtani-Fujita N, Dryja TP, Rapaport JM, Fujita T, Matsumura S, Ozasa K, Watanabe Y, Hayashi K, Maeda K, Kinoshita S, Matsumura T, Ohnishi Y et al (1997) Hypermethylation in the retinoblastoma gene is associated with unilateral, sporadic retinoblastoma. Cancer Genet Cytogenet 98: $43-49$

Panagopoulos I, Kitagawa A, Isaksson M, Morse H, Mitelman F, Johansson $B(2004) \mathrm{MLL} / \mathrm{GRAF}$ fusion in an infant acute monocytic leukemia (AML M5b) with a cytogenetically cryptic ins $(5 ; 11)(\mathrm{q} 31 ; \mathrm{q} 23 \mathrm{q} 23)$. Genes Chromosomes Cancer 41: 400-404

QIU RG, CHEN J, MCCORMICK F, SYMONS M (1995) A role for Rho in Ras transformation. Proc Natl Acad Sci USA 92: 11781-11785

Shapiro DJ, Sharp PA, Wahli WW, Keller MJ (1988) A high-efficiency HeLa cell nuclear transcription extract. DNA 7: 47-55

Weiner MP, Costa GL, Schoettlin W, Cline J, Mathur E, Bauer JC (1994) Site-directed mutagenesis of double-stranded DNA by the polymerase chain reaction. Gene 151: 119-123 
Wilda M, Perez AV, Bruch J, Woessmann W, Metzler M, Fuchs U, Borkhardt A (2005) Use of MLL/GRAF fusion mRNA for measurement of minimal residual disease during chemotherapy in an infant with acute monoblastic leukemia (AML-M5). Genes Chromosomes Cancer 43: $424-426$

Yokota T, Matsuzaki Y, Miyazawa K, Zindy F, Roussel MF, Sakai T (2004) Histone deacetylase inhibitors activate INK4d gene through Sp1 site in its promoter. Oncogene 23: 5340-5349

Yoshiura K, Kanai Y, Ochiai A, Shimoyama Y, Sugimura T, Hirohashi S (1995) Silencing of the E-cadherin invasion-suppressor gene by CpG methylation in human carcinomas. Proc Natl Acad Sci USA 92: 7416-7419

Zhu WG, Otterson GA (2003) The interaction of histone deacetylase inhibitors and DNA methyltransferase inhibitors in the treatment of human cancer cells. Curr Med Chem Anti-Cancer Agents 3: $187-199$ 